\title{
ORDO PRAEDICATORUM: LA COLECCIÓN MUSEOGRÁFICA DE LA IGLESIA DE SANTO DOMINGO DE OSUNA
}

\author{
ORDO PRAEDICATORUM: THE MUSEOGRAPHIC \\ COLLECTION OF SANTO DOMINGO'S CHURCH \\ IN OSUNA
}

\author{
Antonio Morón CARmona \\ Amigos de los Museos de Osuna \\ amoroncarmona@gmail.com
}

\begin{abstract}
El antiguo templo dominico de Osuna, la iglesia de Santo Domingo, que acoge las funciones parroquiales de la colegial de la Asunción, es uno de los edificios de referencia social de los ursaonenses. Su dilatada historia, la monumentalidad de su arquitectura y su amplia colección de bienes escultóricos, pictóricos y de platería, junto a su archivo documental, valieron para crear una colección museográfica permanente titulada Ordo Praedicatorum. En este trabajo se expone el discurso museológico que lo rige junto a la descripción de las piezas que lo jalonan en sus cuatro secciones. La correcta conservación y difusión de estos bienes suman, al uso cultual del templo, un nuevo espacio expositivo acorde con la declaración de conjunto histórico-artístico de la villa.

Palabras claves: Osuna; iglesia de Santo Domingo; colección museográfica Ordo Praedicatorum; discurso museológico; bienes muebles.
\end{abstract}

Santo Domingo's Church, an old Dominican temple in Osuna (Seville), is where are celebrated the parroquial ceremonies of Assumption's Collegiate and one of the social landmarks of the town. This place was chosen to house the museum and permanent exhibit named Ordo Praedicatorum for various reasons, namely, its long history, its monumental architecture, its archive and its magnificent collection of sculptures, paintings and silver ornaments. This paper studies the museum's curatorial standards on the one hand, and of the items that compose the four parts of the collection on the other. The appropriate preservation and dissemination of the exhibits has turned this religious centre of worship into a new exhibition space in accordance with the designation of the town as National Heritage Site.

Keywords: Osuna; Santo Domingo's Church; Ordo Praedicatorum exhibition; curatorial standards; movable goods. 
"Para todos va mi amor, y a todos les pido que me perdonen y que me conserven en sus corazones. Para vosotros y para los niños, mi humilde bendición y súplica". Escribió estas palabras don Alfredo Malo, catedrático en Osuna, ante la intuición cercana de su muerte y fueron publicadas en un libro, en el XXV aniversario de su fallecimiento, como homenaje de sus antiguos alumnos y amigos. Idéntica es la intención que marca la redacción de estas líneas al momento en que esas palabras adquieren una inquietante actualidad en el recuerdo de la doctora doña Lina Malo Lara.

El ancestral campo de Ursino poblado por Pirro, la Colonia Genetiva Iulia otorgada por Julio César, la nueva Jerusalén que construyera en la cabecera de su estado don Juan Téllez-Girón, IV conde de Ureña, y de cuya herencia mística y universitaria se formaran fray Francisco de Osuna o Alonso Lobo; la del cura liberal exaltado Antonio María García Blanco que buscó en sus Viñas el final de sus días y la del cervantista Francisco Rodríguez Marín conforman un vastísimo legado histórico y artístico de la que resulta Osuna, una agraria y empobrecida villa repleta de emblemas que, en los años cuarenta del siglo $\mathrm{XX}$, entroncó con la familia de los Malo y a la que siempre quedarán ligados. Esa herencia recibida es la que despertó en la doctora Malo Lara el interés por las pinturas allí conservadas, murales o de caballete, recogidas en algunas de sus publicaciones. A la profesora Malo también se debe la catalogación de las pertenecientes al antiguo templo dominico de Santo Domingo, con motivo de la inauguración de su colección museográfica Ordo Praedicatorum en diciembre de 2016. Por tanto, esos datos que más abajo proporcionaré no son míos sino suyos, que aquí recojo en agradecido y modesto homenaje.

La llegada de los dominicos a Osuna supone la primera fundación religiosa llevada a cabo por el IV conde de Ureña, entre 1531 y $1547^{2}$, en la ermita de María Santísima y hospital de San Sebastián, desde donde los ballesteros habían defendido sus murallas tras la conquista a los musulmanes por el rey San Fernando $^{3}$. La construcción de su majestuoso templo alberga, entre otros, un solemne y elegante retablo mayor encargado por los frailes en 1582 al arquitectoensamblador Diego de Velasco ${ }^{4}$ y la capilla de los marqueses de Casa Tamayo con su exuberante decoración de yeserías barrocas. De su comunidad salieron figuras

${ }^{1}$ CAMUÑEZ RUIZ, Juan: "Semblanza", en Hijo del entendimiento. Homenaje a don Alfredo Malo, catedrático en Osuna. Osuna, 1992, p. 29.

${ }^{2}$ SÁNCHEZ HERRERO, José: "Osuna. La villa y su gobierno ducal. La iglesia y la religiosidad. 1695-1739”, en Osuna entre los tiempos medievales y modernos (siglos XIIIXVIII). Sevilla, 1995, pp. 340-341.

3 RODRÍGUEZ-BUZÓN CALLE, Manuel: Guía artística de Osuna. Osuna, 1997, p. 75 .

${ }^{4}$ LÓPEZ MARTÍNEZ, Celestino: Desde Jerónimo Hernández a Martínez Montañés. Sevilla, 1929, pp. 143-144. 
destacadas como fray Gabriel Vázquez, catedrático de prima de la Universidad de Osuna, y fray Juan Rubiasco, gran difusor de la devoción al rosario y del que se cuenta que, al morir, se colocaron ramas de naranjo sobre su féretro y florecieron de azahar ${ }^{5}$. Precisamente el convento dominico acogió la gran veneración que se profesaba a la Virgen del Rosario: el Ayuntamiento instituyó anualmente, en 1608, una fiesta solemne el primer domingo de octubre en agradecimiento por la recuperación de don Pedro Téllez-Girón y Velasco, III duque de Osuna, de su enfermedad. También se recurrió a su intercesión para acabar con la sequía en 1683 y, de nuevo, agradeciendo la falta de incidentes tras el terremoto de $1755^{6}$.

Con este bagaje histórico y cultual, el templo de Santo Domingo, que acoge las funciones parroquiales de la de Santa María de la Asunción -la Colegiata-, tiene un gran calado en la identidad colectiva del ursaonés pero llegó a los albores del siglo XXI en un estado ruinoso en su estructura arquitectónica y cuestionable en cuanto a la conservación de su patrimonio artístico. En una triple colaboración no equitativa entre la parroquia, el Arzobispado de Sevilla y el Ayuntamiento de Osuna, entre 2005 y 2016, se llevó a cabo una profunda rehabilitación del edificio y restauración de parte de sus bienes. Su puesta en valor se completó con la iniciativa del párroco y vicario de la zona sur don Antonio Jesús Báez de crear un espacio expositivo permanente que fue encargado a los historiadores don Pedro Jaime Moreno de Soto y don Antonio Morón Carmona, quienes desde hacía unos años se encontraban haciendo los trabajos de inventario de sus bienes muebles.

Para elaborar su discurso expositivo se ha partido, de una parte, del carisma dominico del edificio y de ahí se tomó el nombre de la colección museográfica, Ordo Praedicatorum. De otra, la ubicación en la parte alta, en paralelo a la nave del templo, ha permitido la recuperación de un amplio espacio de lo que queda del convento y ha condicionado la distribución de sus cuatro secciones. De este modo, Laudere, bendecire et praedicare y Veritas -ambos son lemas de la ordenestán dedicados a la liturgia y a los santos dominicos, segunda y cuarta respectivamente. La sección de liturgia se ha hecho coincidir con la trasera del órgano que está visible. La de los santos dominicos permite vincular su contenido con el coro alto, al que se accede por una puerta, cuya sillería posee una colección de pinturas de santos de la orden y supone el final de la visita. La tercera sección, Rosarium, alude a su advocación mariana por excelencia. La introducción y primera sección recoge las devociones que se han profesado en Osuna o tienen un vínculo histórico con ella, por lo que siguiendo la nomenclatura en latín se denominó Pia civitas.

${ }^{5}$ RODRÍGUEZ-BUZÓN CALLE, Manuel: Guía artística..., op. cit., p. 77.

${ }^{6}$ SANTOS MÁRQUEZ, Antonio Joaquín: "La cofradía del Santo Rosario del convento de Santo Domingo de Osuna. Historia, patrimonio y difusión de una devoción", en XVII Simposio sobre Hermandades de Sevilla y su provincia. Sevilla, 2016, pp. 85-110. 
La colección expuesta consta de más de cincuenta piezas de variado soporte -escultura, pintura, textil, platería, joyería, papel y mobiliario- procedente de los propios fondos de la parroquia, donde ha confluido las que permanecen de la presencia dominica como de otras fundaciones desaparecidas -franciscanos de Madre de Dios, mercedarios de la Merced y jesuitas de San Carlos el Real-. Algunas esculturas y pinturas han sido restauradas por alumnos del grado de Bellas Artes de la Universidad de Sevilla y por un equipo dirigido desde el Arzobispado.

Se inicia el primer espacio, Pia civitas, con dos esculturas de Cristo crucificado y la Virgen dolorosa que recogen, de manera general, la devoción a la Pasión y Muerte de Jesús. La primera es de tamaño académico, aparece sobre una cruz poligonal plana y está enmarcada en un dosel policromado en rojo y dorado. Muestra los brazos abiertos en $\mathrm{V}$ mostrando el rigor mortis, con su sencillo sudario cruzado en la parte delantera y la cabeza, con la corona de espinas tallada, desplomada sobre el pecho (Figura 1). La segunda, de mayor tamaño, es de talla completa y proviene de la iglesia de San Carlos el Real. Muestra una actitud itinerante, pues adelanta con fuerza su pierna derecha, acentuada por el amplio volumen de su túnica que deja entrever, como curiosidad, su calzado negro. Inclina la cabeza a la izquierda, mostrando un rictus de hondo dolor en la ondulación de sus cejas y en los labios cerrados. Las manos se entrelazan con angustia y sobre sus brazos sobrevuelan los extremos de su manto recogido. Los ropajes, azules y rojos, cuentan con ribetes estofados más unos amplios adornos florales de rocallas en el caso de la túnica, también estofados. La contrapuesta dirección de la cabeza y la pierna junto a la ampulosidad del ropaje otorgan un aire monumental a la escultura en contraste con el íntimo sentimiento que infunde su rostro (Figura 2). La posición de las cejas y la boca abierta del Crucificado y la similitud de la Dolorosa con el busto conservado en la iglesia del Sagrario de Granada permitieron al historiador Moreno de Soto adjudicarlas a José Montes de Oca y Torcuato Ruiz del Peral respectivamente, resultando dos relevantes ejemplos de las escuelas sevillana y granadina del siglo XVIII en Osuna.

En la configuración de la iconografía de la Virgen dolorosa tuvo un protagonismo destacado doña María de la Cueva y Álvarez de Toledo, hija del II duque de Alburquerque y esposa del IV conde de Ureña. Tras enviudar, el rey Felipe II la eligió como camarera mayor de la reina Isabel de Valois, coincidiendo hacia 1565 y 1566 con el encargo de la soberana, al escultor Gaspar de Becerra, de una imagen de la Virgen de la Soledad a la que profesaba devoción. A la condesa viuda le correspondió ataviar a la nueva imagen, realizando con esta la tarea que hacía cada día con la reina: controlar su guardarropa, elegir las joyas y mandar a hacer los trajes que necesitaba. De este modo la vistió “de soledad y viudez", como cuentan las narraciones, con manto negro y una amplia toca blanca que solo dejaba visible el rostro. Tras depositarla en el convento de la Victoria de Madrid, de 
los frailes mínimos, su devoción se extendió por toda la península ${ }^{7}$. La existencia de un lienzo de gran formato de la Virgen de la Soledad, fechado a mediados del siglo XVII, y el singular quehacer de la condesa viuda de Ureña los justifican dentro del discurso museológico. Su presencia en el templo dominico nos hace dudar de si pertenece a él o pudo venir del cercano convento de los mínimos de la Victoria. Por unos inventarios consultados en este último, se conoce la existencia de una pintura "en los costados del arco de entrada [de la actual capilla de María Auxiliadora] hay uno grande de S. Francisco de Paula y otro que representa la Soledad de Nuestra Sra. con marcos de madera". A día de hoy no existen allí y cabe conjeturar acerca de si el adjetivo "grande" también se refería al de la Soledad por lo que, siendo así y atendiendo a la vinculación histórica entre la advocación de la Soledad y los mínimos, si se trata del mismo, aventurando un posible traslado, a mediados del siglo $\mathrm{XX}$, de un templo a otro por algún motivo desconocido. En cualquier caso, se reproduce a la Virgen de la Soledad en su altar, sobre una doble grada cubierta de manteles blancos terminados en puntas semicirculares, donde se apoyan sendos jarrones con flores y otras desparramadas, enmarcándose entre un cortinaje rojo recogido. La Virgen, como es habitual, aparece arrodillada, con la cabeza inclinada y las manos entrelazadas, vestida de la manera ya descrita y con ráfaga de rayos ondulados y lisos en su cabeza. Lamentablemente, su estado de conservación es muy precario.

La devoción a la Virgen de los Dolores se incrementó en Osuna a partir de la creación de la Venerable Orden Tercera de los Siervos en $1719^{9}$, en el ya mencionado convento de los mínimos, en torno a una soberbia escultura atribuida tradicionalmente a José de Mora. La reproducción de la Dolorosa en pequeño formato tuvo su desarrollo destinado a oratorios particulares. Para su representación se requirió de añadidos de tejidos, joyas y atributos argénteos. De esa puesta en escena, configurada por elementos simbólicos, es ejemplo la Virgen de los Dolores del siglo XVIII ${ }^{10}$ y expuesta en su propia hornacina, muy popular entre la feligresía de la iglesia que nos ocupa. Su rostro sereno y las palmas de sus manos posadas una sobre otra se completan con manto y túnica de terciopelo azul y rojo bordados en oro, enaltecida con peana, ráfaga, corona y media luna labradas en plata, mientras que el corazón con los siete puñales sobre el pecho

${ }^{7}$ ROMERO TORRES, José Luis: "La condesa de Ureña y la iconografía de la Virgen de la Soledad de los frailes mínimos (I)", Cuadernos de los Amigos de los Museos de Osuna, 14, 2012, pp. 55-62.

${ }^{8}$ APVO (Archivo Parroquia de la Victoria de Osuna), Inventarios 1922-1956, s. f.

9 AGAS (Archivo General del Arzobispado), Justicia, Hermandades, leg. 163-A, Autos de erección y aprobación de la V.O.T. de María Santísima de los Dolores, 1780, f. 1.

${ }^{10}$ MORENO DE SOTO, Pedro Jaime y ROMERO TORRES, José Luis: A Imagen y Semejanza. Escultura de pequeño formato en el patrimonio artístico de Osuna. Osuna, 2014, p. 46. 
está sobredorado. En dicha peana, ráfaga y corona aparece repetida la marca "V. GARGALLO", perteneciente a Vicente Gargallo, maestro platero de fábrica del Arzobispado de Sevilla entre 1786 y 1802, lo que denota la calidad requerida por el comitente ${ }^{11}$.

Otras dos pinturas expuestas en esta primera sección entroncan, directamente, con dos devociones de gran identidad ursaonense. La primera tiene formato apaisado, es de discreta calidad y se puede interpretar como una Alegoría a la sangre de Cristo. A diferencia de otras con la misma temática, donde aparece el Crucificado sobre la fuente de la salvación, en esta obra una pareja de ángeles volanderos sostienen un sudario en cuyo centro está la figura de Jesús de la $\mathrm{Hu}$ mildad y Paciencia, con las manos entrelazadas, sentado sobre un taburete. Ante su presencia, se simultanea un cruento paisaje con el martirio de los once apóstoles más la degollación de San Pablo, con el nombre de cada uno abajo, y entre los que el anónimo pintor local del siglo XVIII ha incluido el martirio de San Arcadio, patrón de Osuna desde 1642 (Figura 3). Su presencia se ha completado con la exposición de un ejemplar de la Historia, Vida y Martirios del Glorioso Español San Arcadio Ursaonense. Su autor, el agustino fray Fernando de Valdivia, fue un ilustre ursaonés nacido en el último tercio del siglo XVII, teólogo por la universidad de Osuna. Se cree que este libro fue escrito a finales del siglo XVII a petición de don Arcadio Chirinos, mayordomo entonces de la Ilustrísima Cofradía de San Arcadio y se imprimió en la imprenta San Agustín de Córdoba en 1711 ${ }^{12}$.

La primera sección se concluye con una pintura que alude a la ferviente devoción que don Juan Téllez-Girón, IV conde Ureña, profesaba a la Virgen Inmaculada. A este misterio consagró la fundación del Colegio-Universidad de la Santa Concepción de Osuna en 1548, situándola entre las primeras universidades en exigir su defensa entre los docentes y alumnos. Osuna debió vivir un ambiente de exaltación en la defensa concepcionista hasta el punto que un agustino se vio envuelto en una serie de acusaciones promovidas por los dominicos que elevaron hasta la Inquisición, con motivo de un polémico sermón que pronunció en alabanza a la concepción sin pecado de la Virgen. La concordia se escenificó cuando dominicos y franciscanos fueron del brazo en la procesión de la Inmaculada Concepción que organizaron los jesuitas ${ }^{13}$. Este episodio se muestra con una Inmaculada Concepción pintada en un taller sevillano hacia 1670-1680, que sigue la iconografía recomendada por Pacheco y cuyo autor conoce los modelos murillescos: la Virgen aniñada con mirada baja, vestida de blanco y celeste, situada

${ }^{11}$ CRUZ VAldovinOS, José Manuel: Cinco siglos de platería sevillana. Sevilla, 1992, p. 363.

12 RODRÍGUEZ-BUZÓN CALLE, José María: "Prólogo a la reedición”, en Historia, Vida y Martirios del Glorioso Español San Arcadio Ursaonense. Osuna, 1994, pp. X-XI.

${ }^{13}$ MORENO DE SOTO, Pedro Jaime: Dogma, poder e ideología. La Casa de Osuna y la devoción a la Inmaculada Concepción. Osuna, 2006, pp. 141-153. 
sobre una nube con la media luna a modo de escabel, sobre un fondo ocre con cabezas de ángeles en la parte superior y otros de cuerpo entero en la inferior que sostienen una palma, único símbolo en torno a la imagen. Junto a ella, se exponen sendas joyas del ajuar de la Virgen del Rosario: una insignia de cofradía de San Francisco, en bronce esmaltado con una miniatura pintada de dicho santo, de hacia 1701-173014, y un colgante de cristal con la cruz dominica pintada.

La vista de la trasera del órgano en el espacio expositivo, como se ha indicado más arriba, dio pie a la sección dedicada a la liturgia. Dicho órgano podría datarse hacia 1760, cuenta con cinco castillos con prominente torreón central sobre ménsula, separado por pilastras con decoración de flores y guirnaldas (Figura 7). El conjunto se cierra con una exuberante crestería calada con motivos de roca$11 a s^{15}$. Para la reapertura del templo, ha sido intervenido por el maestro organero Gerhard Grenzing. El lema dominico Laudere, bendecire et praedicare, el carácter sacro de la colección museográfica y la función que desempeña el edificio encajaban bien para mostrar en esta sección los ornamentos sagrados, textiles y de platería, que se usan en las celebraciones religiosas.

De un lado, parte de un terno compuesto por capa pluvial y casulla de tisú de plata bordado en hilo de oro y sedas de colores con la técnica de cartulina, reproduciendo motivos florales y de roleos, del siglo XIX. De otro, un par de ostensorios, coetáneos en el tiempo y casi idénticos en su forma y decoración neoclásica. El primero cuenta con la leyenda en la base "SE ISO CON EL PRODVCTO DE LA CATEDRA Y DOCTORADO ĐL R. P. F. MANUEL MARUFQ LECTOR JVBILADO EN ESTE CONVENTO Đ LA OBSERVANCIA DE N.P. S. S. FRANCISCO DOCTOR EN ARTES TEOLOGÍA I ARTES I CANONES I CATEDRÁTICO DE LVGARES TEOLOGICOS EN LA INSIGNE UNIVERSIDAD Đ OSUNA. AÑO DE 1817". Tiene la marca "ASCONA", del cordobés Manuel Azcona Martínez, y destacan dos escudos con el abrazo de San Francisco y la cruz de Jerusalén. En el segundo se lee: "SE HIZO ESTA CVSTODIA CON LIMOSNAS Qe DIERON LOS FIELES Đ OSUNA Y DOS R. S. V. E. SUPLIO EL CONVTO. Đ N. P. STO DOMINGO P. A. SV CONCLY. N. SIEN.O. PRIOR EL M.R.P. PRES. DO FR. FRAN.O VSAGRE. AÑO 1816". Tiene la marca "AGVI", del también cordobés Manuel Aguilar y Guerrero, apareciendo en una cartela el cordero eucarístico.

Se continúa con un dispar grupo de cálices. El más antiguo puede datarse a mediados del siglo XVI por su ornamentación renacentista, con hojarascas estilizadas grabadas en la base y costillas en la copa (Figura 4). Es difícil asegurar que pertenezca a la fundación de los dominicos, ya que pudo llegar de la colegiata

${ }^{14}$ ARBETETA MIRA, Letizia: El arte de la joyería en la Colección Lázaro Galdiano. Madrid, 2003, pp. 34-141.

15 AYARRA JARNÉ, José Enrique: Órganos en la provincia de Sevilla. Inventario y catálogo. Granada, 1998, pp. 216-218. 
como ocurrió con la dispersión de algunos vasos sagrados cuando se crearon las otras dos parroquias en 1911. Los dos siguientes tienen base y nudo del siglo XVII, pero sus copas fueron repuestas en el siglo XVIII y XIX respectivamente. El primero destaca por su fina y elegante decoración también renacentista, vegetal y geométrica; el segundo se caracteriza por unos tondos alados con cruces, por su abultado y desproporcionado nudo y la copa donde se reproducen grabadas las hojarascas de la base. Del siglo XIX se conservan cuatro ejemplares. Uno es neobarroco sin decoración, proveniente de Écija como se puede leer: "ZOY DEL ARPP F FRANCISCO FERNANDEZ PRIOR DEL CARMEN CALZADO Đ ECIJA AÑO 1815". Tiene las marcas "MARTINEZ", "A RUIZ” y el león rampante de Córdoba, por lo que su autor es el platero cordobés Antonio Ruiz León. Otro mantiene la forma neobarroca pero se cubre por hojas de laurel, con la marca "A/MAST" de 1872. Los dos últimos son neogóticos y dorados, destacando el que perteneció a un ursaonés cuya personalidad es de las más relevantes de la segunda mitad del siglo XIX: "EN GRATIA Dn VICTORIANO APARICIO" de 1891. El sacerdote don Victoriano Aparicio, perteneciente a una familia de comerciantes, rigió la colegial del Salvador de Sevilla y ejerció como profesor de Teología Pastoral en el Seminario Metropolitano. La enfermedad lo devolvió a su villa natal donde se hizo cargo de la iglesia de Santo Domingo, que la convirtió en centro de la vida religiosa de Osuna. Rodríguez Marín, a cuya pluma pocas personas habían logrado salir bien paradas, escribió de él en 1887: es persona iletrada sin pedantería, elocuente sin afectación y piadosa sin hipocresía ${ }^{16}$.

Una mayoritaria presencia de piezas decimonónicas da cuenta de una renovación de su ajuar paralelo al proceso que experimentan los monasterios de San Pedro ${ }^{17}$ y de la Encarnación ${ }^{18}$. Las piezas de platería se completan con una interesante y pequeña lámpara aceitera de perfil abombado y escalonado, de decoración manierista protobarroca del siglo XVII; un juego de vinajeras y salvilla lisas marcadas con "39C.LEON" y el león rampante, del también cordobés Cristóbal José de León de 1839; y un portaviático con cadena para colgar al cuello, sobre base mixtilínea y cuerpo central con haces de rayos plisados alrededor del cordero eucarístico y culminado por una corona, marcado por "MRTNEZ", Mateo Martínez Moreno, de 1798.

La devoción al Rosario difundida por los dominicos ocupa, sin duda, un espacio ineludible en la colección museográfica (Figura 5). Se inaugura con una pintura de la Virgen del Rosario, antaño ubicada en la capilla del mismo nombre

${ }^{16}$ RAMÍREZ OLID, José Manuel: Osuna durante la Restauración. 1875-1931. Vol. II. Osuna, 1999, pp. 753-756.

17 MORÓN CARMONA, Antonio: "Platería y joyería", en Fuga Mundi I. Clausuras de Osuna. El monasterio carmelita de San Pedro. Osuna, 2014, pp. 198-207.

${ }^{18}$ MORÓN CARMONA, Antonio: "La venta de la platería en el monasterio de la Encarnación de Osuna (1807-1866)", Laboratorio de Arte, 29, 2017, pp. 837-843. 
y que, a criterio de la doctora Malo Lara, pertenece a un anónimo seguidor de Murillo en la segunda mitad del siglo XVII (Figura 6). El tema iconográfico representa a la Virgen con el Niño Jesús a modo de una Virgen de Belén, pero se ha añadido un rosario que pende del dedo índice de la delicadísima mano derecha de María. El enternecedor abrazo materno-filial, la inclinación de la cabeza de la madre sobre la del hijo, el ademán de este a punto de acariciarle el rostro, la calidez de la escena sobre el rotundo fondo negro, sus comedidas sonrisas, la transparencia y vaporosidad de los tejidos, especialmente el pañal blanco del Niño, le confieren una gran calidad. Se remata con un magnífico marco de hojarascas barrocas, rematado arriba por una venera y una cabeza alada en la parte baja. Esta pintura fue restaurada por alumnos de la facultad de Bellas Artes de la Universidad de Sevilla. Una obra que comparte los rasgos en cuanto a la posición de las imágenes es su homónima de la catedral de Jerez de la Frontera.

A la par de la elaboración del discurso museológico, el doctor Santos Márquez publicó nuevos datos sobre la cofradía del Santo Rosario que permitió documentar algunas piezas. En 1648 se renovó completamente su capilla gracias a la munificencia de uno de sus más ilustres hermanos, don Juan Muñoz Bocos, tal y como aparece en una inscripción en el zócalo de mármol rojo sobre el que se apoya el retablo. En la colección museográfica está expuesta la puerta del sagrario del retablo de dicha capilla, emparentada con el taller sevillano de Felipe de Ribas $^{19}$, en la que se representa el Niño Jesús sosteniendo la bola del mundo enmarcado en una portada con frontón curvo. También, el arca de tres llaves de la cofradía, realizado en 1653 por Diego Márquez ${ }^{20}$, con sendas miniaturas pintadas de la propia Virgen del Rosario y San Sebastián, algo perdidas pero interesantes al darnos cuenta de la fusión de las dos corporaciones tres años antes y porque la representación de la Virgen se corresponde con una escultura anterior a la actual. Para el rezo público del rosario se usaba un espléndido simpecado de gala, que se encuentra enmarcado, de terciopelo rojo con bordados de motivos vegetales en hilos de oro y dos escudos dominicos en sus puntas, destacando la pintura que lo preside, de la Virgen entregando el rosario a Santo Domingo y Santa Rosa de Lima, del círculo de Bernardo Lorente Germán hacia $1740^{21}$. Por último, una pequeña campana de plata, con la que se avisaría de la oración por las calles, con la inscripción "SOY DEL ROSARIO DE LAS SEÑORAS MUGERES DEL CONBENTO Đ N. SP.TO DOMINGO DE LA VILLA DE OSSUNA DEL AÑO Đ 1766".

\footnotetext{
19 SANTOS MÁRQUEZ, Antonio Joaquín: “La cofradía del Santo...”, op. cit., p. 99.

${ }^{20}$ Ibidem, p. 101.

${ }^{21}$ Ibid., p. 106.
} 
Se tiene constancia de otra cofradía rosariana en Santo Domingo, la Congregación de la Aurora o del Rosario de la Aurora ${ }^{22}$. En agosto de 1698, la comunidad de frailes dominicos con fray Juan del Busto a la cabeza firmó ante escribano público con don Antonio Luis, don Andrés de Luna y don Juan de Dios Catario "del Rosario de María Santísima que sale todos los días por la madrugada y llaman del Rosario de la Aurora", la cesión, renuncia y traspaso de tres sepulturas para que "dichos hermanos y hermanas se entierren en ella". El coste de dichas sepulturas sumaba 330 reales y se encontraban contiguas a la grada de la entrada de la capilla mayor, "entre los altares de Santa Catalina y Santa Rosa"23, hoy inexistentes en el templo. De esta cofradía, de la que apenas conocemos su misión cultual con el rezo del rosario y caritativa mediante el entierro de sus herma$\operatorname{nos}^{24}$, ha permanecido la escultura de su titular, la Virgen de la Aurora, una obra de poco más de $15 \mathrm{~cm}$, fechada en el siglo XVIII ${ }^{25}$, llena de delicadeza y belleza. Aparece en una curiosa posición similar a la postura de meditación, sentada con las piernas cruzadas y levantando la mano derecha, y en su regazo acoge al Niño Jesús dormido. Su pequeño rostro muestra unos rasgos juveniles, como una tímida doncella de mirada baja y con una cabellera peinada al centro en una raya que se abre frondosamente cayendo a la espalda sobre su manto celeste. Se eleva sobre una peana barroca de carrete y cuenta con corona y una diminuta campanita de plata en la mano del niño. La otra pieza expuesta de esta congregación es un lienzo de un pintor anónimo local de hacia 1760. Muestra a la Virgen entregando el rosario a Santo Domingo y a Santa Catalina de Siena; su trasera está cubierta por otro lienzo con un gran escudo dominico y la inscripción "AVRORA 18 ", correspondiendo a una fecha, pero está roto. Su marco dorado de rocallas le otorga una gran vistosidad.

Junto a las cofradías existentes en Santo Domingo, se erigen otras en la villa con la misma advocación, entre ellas la de Ánimas del Rosario del convento de la Merced, de $1795^{26}$, fusionada a comienzos del siglo XIX con la hermandad penitencial de Nuestro Padre Jesús Caído. En un inventario de 1873, se describe "un cuadro dorado de madera con la imagen de Nuestra Sra. del Rosario, con corona, cetro y media luna de plata y el Niño corona y cetro de lo mismo. Al reverso tiene este cuadro las ánimas y termina en una corona de madera dorada y tiene además

${ }^{22}$ ROMERO MENSAQUE, Carlos José: El Rosario en la provincia de Sevilla. Sevilla, 2010, p. 185.

${ }_{23}$ AMO (Archivo Municipal de Osuna), Protocolos Notariales, Leg. 518, Tomás de Paz, 1968, ff. 472-474v.

${ }^{24}$ GUTIÉRREZ NÚÑEZ, Francisco Javier: "Una visión cultural de los testamentos ursaonenses a finales del siglo XVIII", Apuntes 2, 4, 2004, p. 80.

${ }^{25}$ MORENO DE SOTO, Pedro Jaime y ROMERO TORRES, José Luis: A Imagen..., op. cit., p. 42.

${ }^{26}$ ROMERO MENSAQUE, Carlos José: El Rosario en ..., op. cit., p. 184. 
su asta de madera" ${ }^{27}$. Se trata de la insignia de la referida cofradía que forma parte, también, de la colección expuesta. La doble pintura, de un pintor anónimo local, cuenta con otro marco de rocallas doradas sobre fondo negro, concebido a modo de estandarte para ser portado y visto por ambas caras. Efectivamente, se representa a la Virgen entregando el rosario a las ánimas sobre la letanía escrita “CONSOLATRIX AFLICTORVM ORA PRO NOBIS". En la trasera, una pareja de ángeles volanderos también entregan el rosario a las ánimas que padecen entre llamas. No se ha conservado la corona descrita que remataba el conjunto y los atributos de plata se encuentran desmontados pendientes de su colocación.

La última sección del discurso museológico, Veritas, alude a la dedicación al estudio y defensa de la verdad sagrada que procuran los frailes dominicos, rasgo que les valió para que el papa Gregorio IX les confiase la gestión del Santo Tribunal de la Inquisición. La asociación para siempre de ambas instituciones quedó patente en el escudo de la Inquisición que aparece en el ático del retablo de San José, en el banco del de San Juan Nepomuceno o en el del Cristo amarrado a la columna. También, en una cruz procesional ahora expuesta, atribuida a un taller andino. De perfil alabeado, su superficie se cubre por rocallas aveneradas muy planas, en la que aparecen elementos alusivos a la orden dominica, como la pareja de perros con la antorcha, su emblema y el de la Inquisición ${ }^{28}$.

Tres pinturas de gran formato le siguen, comenzando por una obra anónima local de hacia 1760 que nos remonta a un momento anterior a la creación de la propia orden: la leyenda del Sueño de la beata Juana de Aza, madre de Santo Domingo. La escena, ubicada en un gabinete descubierto por un cortinaje, recrea a la citada beata Juana encinta y durmiente sobre su brazo que apoya en un escritorio, donde hay un par de libros, tinteros y un crucifijo, mientras aún aguanta en la otra un libro más. Juana de Aza está vestida siguiendo la moda femenina de la cronología del cuadro, con camisa blanca rematada en encajes en el cuello y mangas, con vestido violáceo y jubón de color ocre, ajustado con cinturón con un botón-joya y un aderezo de pendientes y collar de perlas, estando cubierta su cabeza por un velo. El referido sueño, en que imaginó que llevaba un perro en el vientre y que saltaba fuera con una antorcha en la boca, se resuelve en el ángulo superior derecho, en una nube donde reposa un gracioso can apoyado en el orbe y con la antorcha. Abajo contiene la inscripción "LA BEATA JUANA DE AZA MADRE DE NTRO AMADO PADRE EL GRAN DOMINICO DE GUZMÁN FVNDA Đ SAGRADO ORDEN STO DOMINGO”. La discreta factura

${ }^{27}$ AHJCO (Archivo de la Hermandad de Jesús Caído de Osuna), Inventario de los efectos y alhajas propios de la Cofradía de Nuestro Padre Jesús Caído y Ánimas. Osuna y abril de 1879, s. f.

${ }^{28}$ SANTOS MÁRQUEZ, Antonio Joaquín: "La platería Iberoamericana en Osuna y su Ducado", en Ophir en las Indias: estudios sobre la plata americana: siglos XVI-XIX. Sevilla, 2010, p. 545. 
pictórica se ve hermoseada por el fabuloso marco de rocallas que alberga cuatro pinturas más: el papa Pío V, Santo Domingo, San Alberto Magno y Santa Rosa de Lima. Una búsqueda en internet sobre esta beata, dio con el hallazgo de un grabado idéntico al lienzo que nos ocupa, con las firmas "J. Alt ${ }^{\mathrm{a}}$ lo dib\% $\%$. Boix lo gr. ${ }^{\circ} \mathrm{a}^{\circ} .1828$ " y el texto abajo: "BTA JUANA DE AZA, MADRE DE SANTO DOMINGO DE GUZMÁN FUNDADOR DEL ORDEN DE PRESDICADPRS", del archivo de Máximo López, por lo que queda por averiguar la repercusión de esta obra para que saltara al grabado años después de su ejecución.

Frente a este lienzo, otro que representa a Santo Domingo de Guzmán y que hace pareja con la Inmaculada Concepción descrita más arriba, lo que da cuenta de un encargo de la orden para reforzar su apego a la defensa inmaculista. Se muestra de figura completa como fundador de la orden, vestido con hábito y enarbolando una banderola con el emblema dominico, mientras sostiene en la mano derecha una vara de azucenas y aparecen otros elementos identificativos como el perro con la antorcha y los evangelios.

Sin duda, la gran obra pictórica de la colección, que preside el testero final del espacio museográfico, es el Santo Domingo en Soriano de Juan del Castillo, uno de los pintores más representativos del panorama artístico sevillano, en la primera mitad del siglo XVII (Figura 8). Entre sus obras relacionadas con los dominicos están las cuatro versiones que de este asunto realizó para otros tantos conventos: hacia 1625 para el convento de Madre de Dios de Carmona, en 1626 y 1627 el de Madre de Dios de Sevilla, entre 1625 y 1630 el destinado para Osuna y de hacia 1635 el del convento de Monte-Sión de Sevilla ${ }^{29}$.

Para la obra expuesta en Osuna, Juan del Castillo copió el homónimo del pintor Juan Bautista Maíno de 1629, que actualmente se conserva en el Museo del Hermitage en San Petersburgo. La composición se divide en dos mitades unidas por el brazo derecho de la Virgen María: a la izquierda aparece Santa Catalina de Alejandría que sostiene con sus manos el lienzo con Santo Domingo de Guzmán y, arrodillado sosteniéndolo también, fray Lorenzo da Grottaria. En el lado contrario se sitúa la Virgen María vestida con túnica roja y manto azul, siendo ese tono rojo identificativo del autor, y con un finísimo velo transparente cubriendo su cabeza, acompañada por María Magdalena con cabellos rubios, lo que denota la influencia de la pintura flamenca. De entre los otros cuadros homónimos solo en el de Osuna y a la Magdalena es a la única que se le pintan los pies calzados con sandalias, un detalle que refuerza la tendencia al naturalismo.

La composición ursaonense es similar al cuadro de hacia 1625 del convento de Madre de Dios de Carmona, estando en este los protagonistas femeninos más separados entre sí y el hecho de que la Virgen participe, también, a la hora de sostener el retrato de Santo Domingo. Igualmente comparten el espacio

${ }^{29}$ MALO LARA, Lina: "Pinturas de Juan del Castillo para la Orden Dominica", Laboratorio de Arte, 19, 2006, pp. 475-480. 
arquitectónico gótico en que sucede la escena milagrosa, una recreación del convento de Soriano, más nítido en el de Carmona, mientras que en el de Osuna esas formas no son tan evidentes, predominando cierto tenebrismo. Dicho fondo arquitectónico sirve como excusa para incluir una escena religiosa más: en Carmona la Crucifixión y en Osuna la Anunciación, por lo que vuelve a reforzar la presencia mariana en la Orden de Predicadores. El porte solemne de las figuras y la textura de sus tejidos zurbaranescos se mantienen en las versiones de Osuna y del convento de Monte-Sión de Sevilla. El lienzo se inserta en un rico marco de madera tallada y dorada de mediados del siglo XVIII, con sendos estípites como sustento del pabellón superior y ornamentación de rocallas.

El discurso museológico de la colección Ordo Praedicatorum termina, al igual que las presentes líneas, en el coro alto, donde su tosca sillería cuenta con más de treinta sitiales que acogen pinturas sobre tabla, de muy discreta calidad, de santos dominicos o emparentados con la orden. Entre ellas destaca la del prior cuyo respaldo, culminado por el escudo dominico, acoge una presentación de la Virgen entregando el rosario a Santo Domingo y Santa Rosa de Lima, arrodillados y entre ellos el perro con la antorcha, y una inscripción que cuenta que "EL DIA 4 Đ ABRIL Đ L AÑO Đ 1742, A LAS 10 ĐE LA MAÑANA CAIO UN RAIO EN LA TORE Y Đ ALLI BAJO AL CORO DESTRUYO ESTAS TRES SILLAS, NO Q.DANDO ENTERAS SINO ESTA PEQÑA IMAGEN Đ N. S ${ }^{\text {. }}$ AVIENDO. LASTIMADO LAS Đ MAS SILLAS I HECHO OTROS ESTRAGOS BAXO A LA PVERTA PRINCIPAL [...] TRATANDOLA SIN A VER OFEN. DIDO A NADIE [...] S INTITV Đ L RAIO POR MEMORIA".

Fecha de recepción: 30 de octubre de 2017

Fecha de aceptación: 12 de abril de 2018 


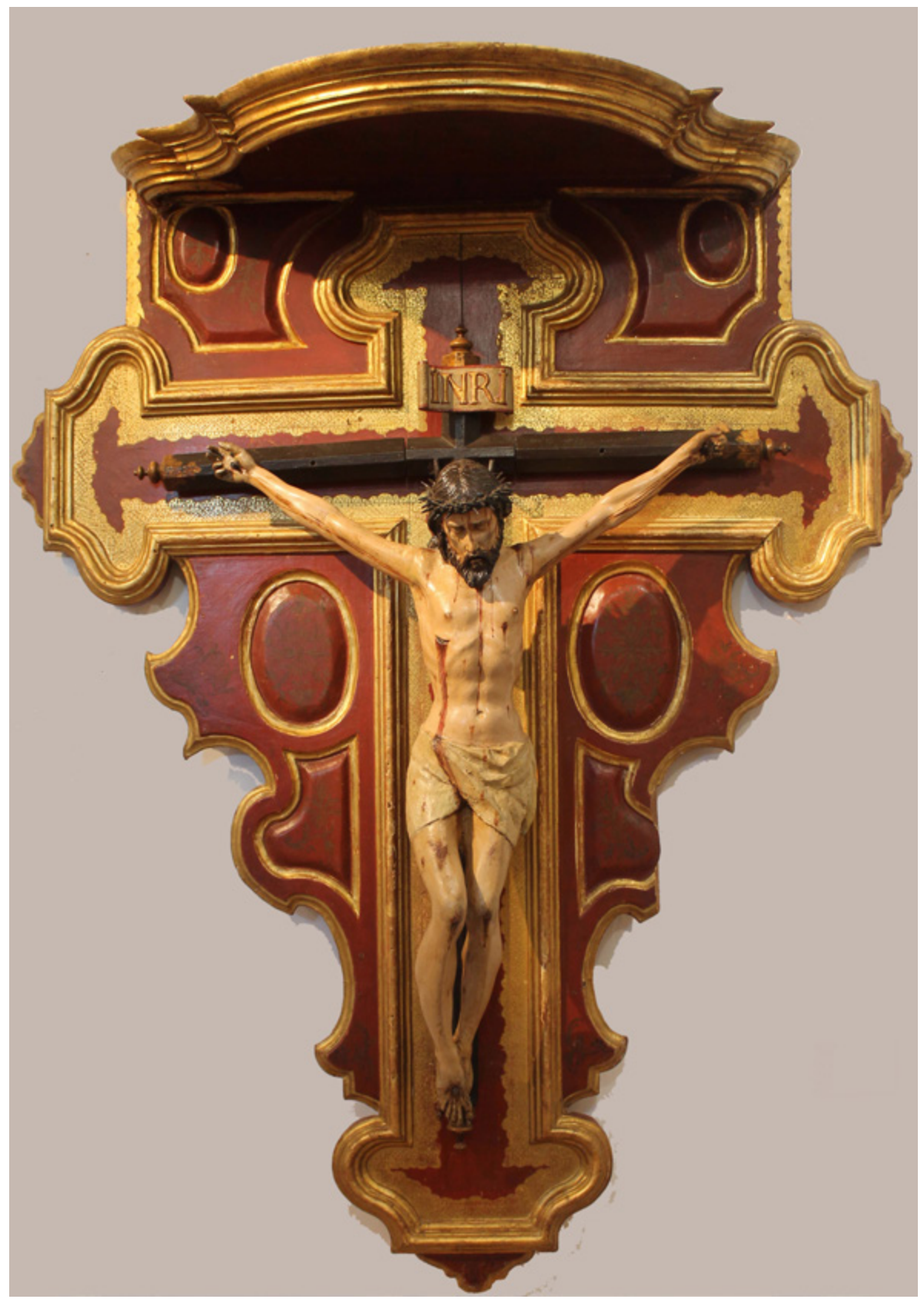

Figura 1. Atribuido a José Montes de Oca, Cristo Crucificado. Foto: Carlos Fernández. 


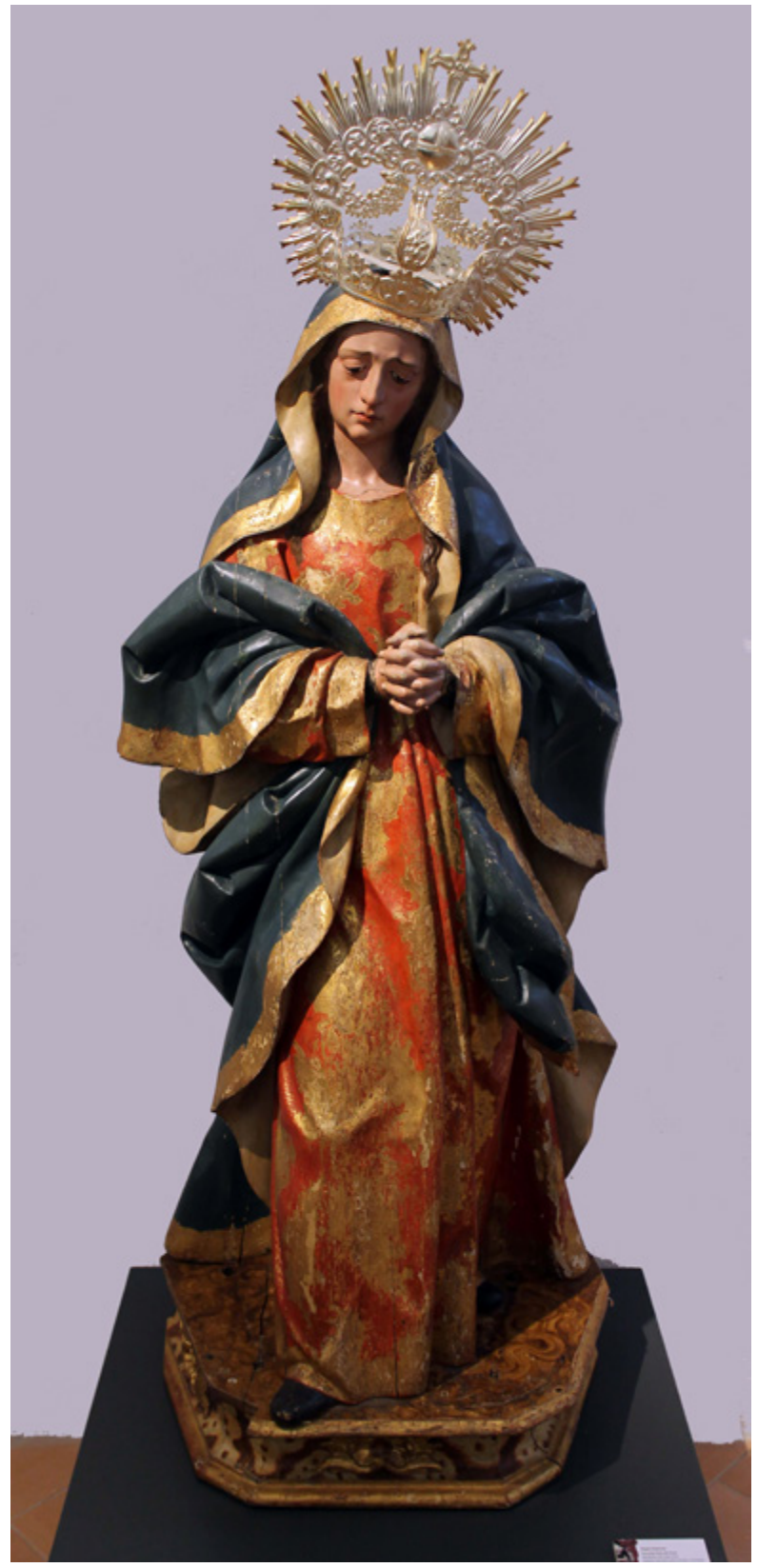

Figura 2: Atribuida a Torcuato Ruiz del Peral, Virgen Dolorosa. Foto: Carlos Fernández. 


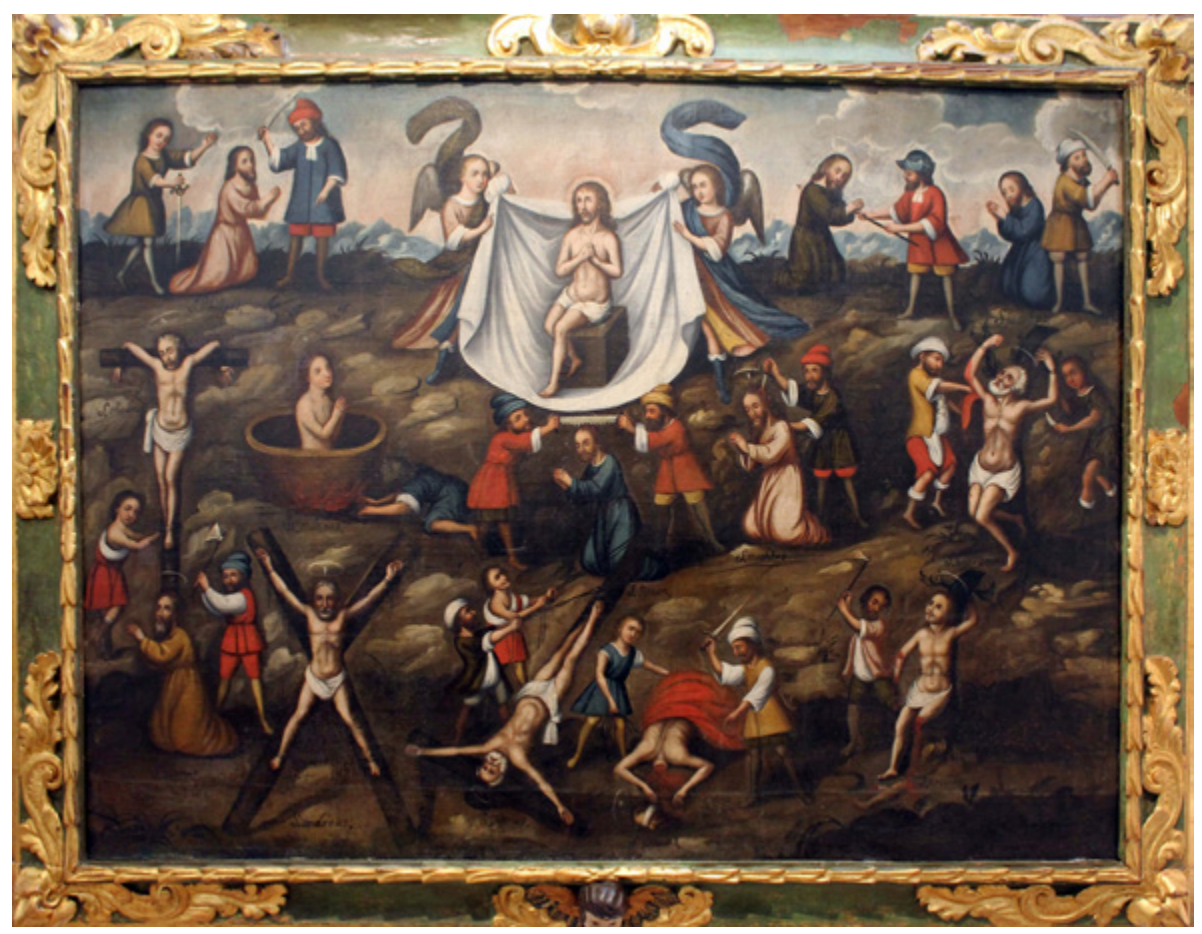

Figura 3. Anónimo local, Jesús de la Humildad y Paciencia junto al martirio de los apóstoles y San Arcadio, siglo XVIII. Foto: Carlos Fernández. 


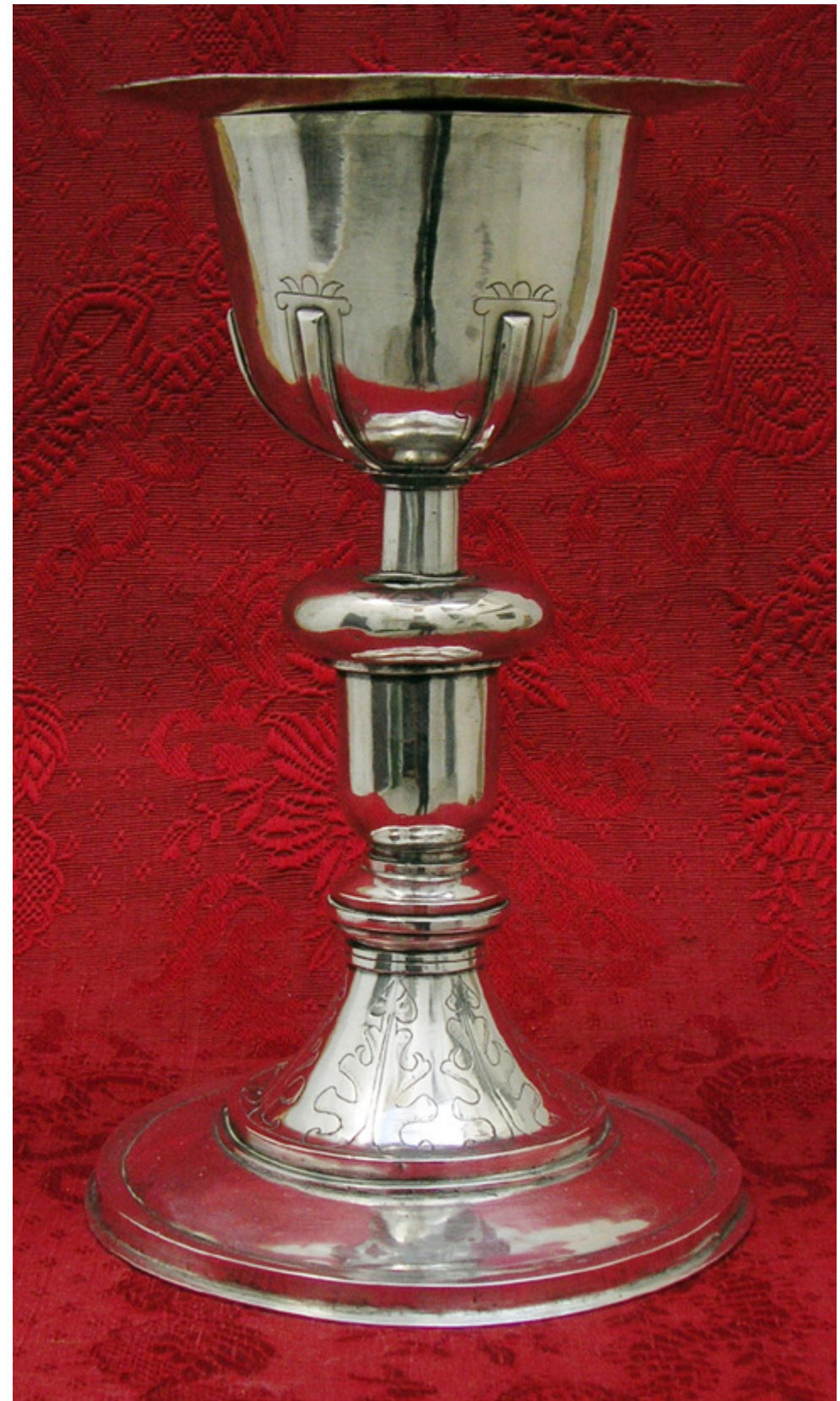

Figura 4. Cáliz de plata de estilo renacentista, mediados del siglo XVI. Foto: Antonio Santos. 


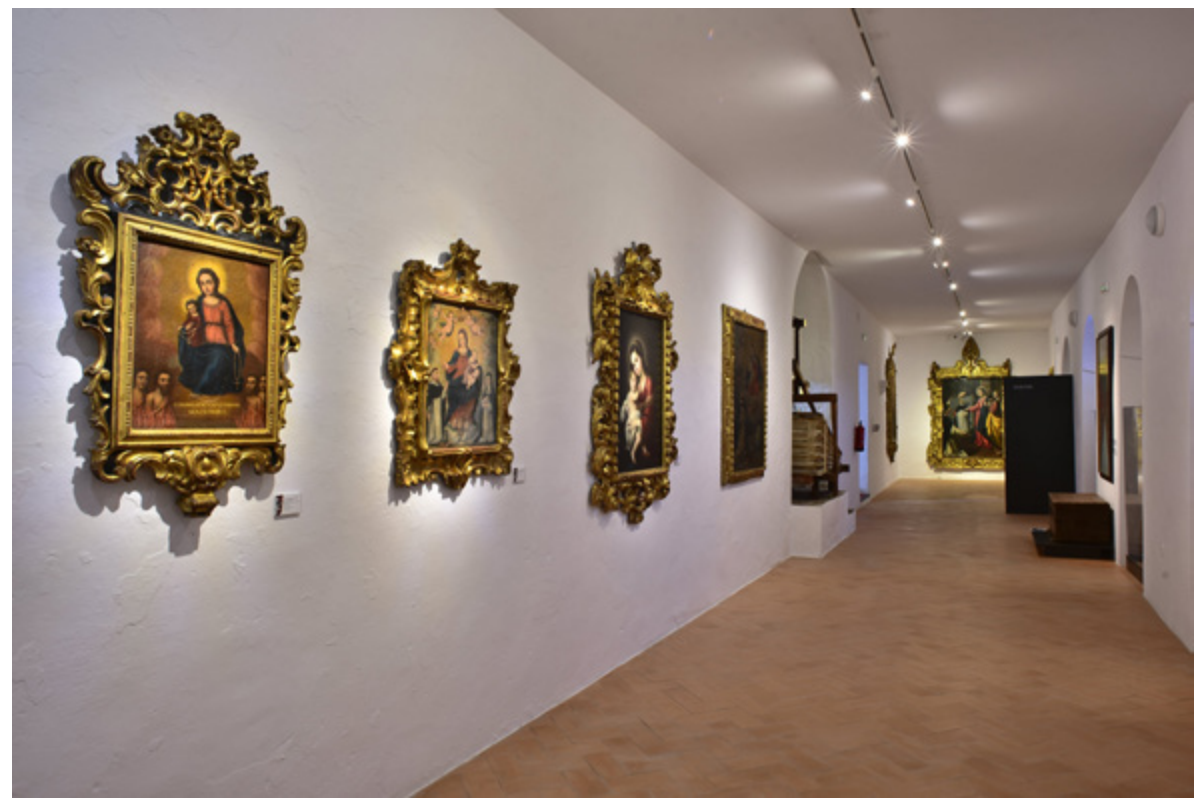

Figura 5. Vista de la sección Rosarium, con diversas pinturas dedicadas a esa advocación. Foto: Oscar González. 


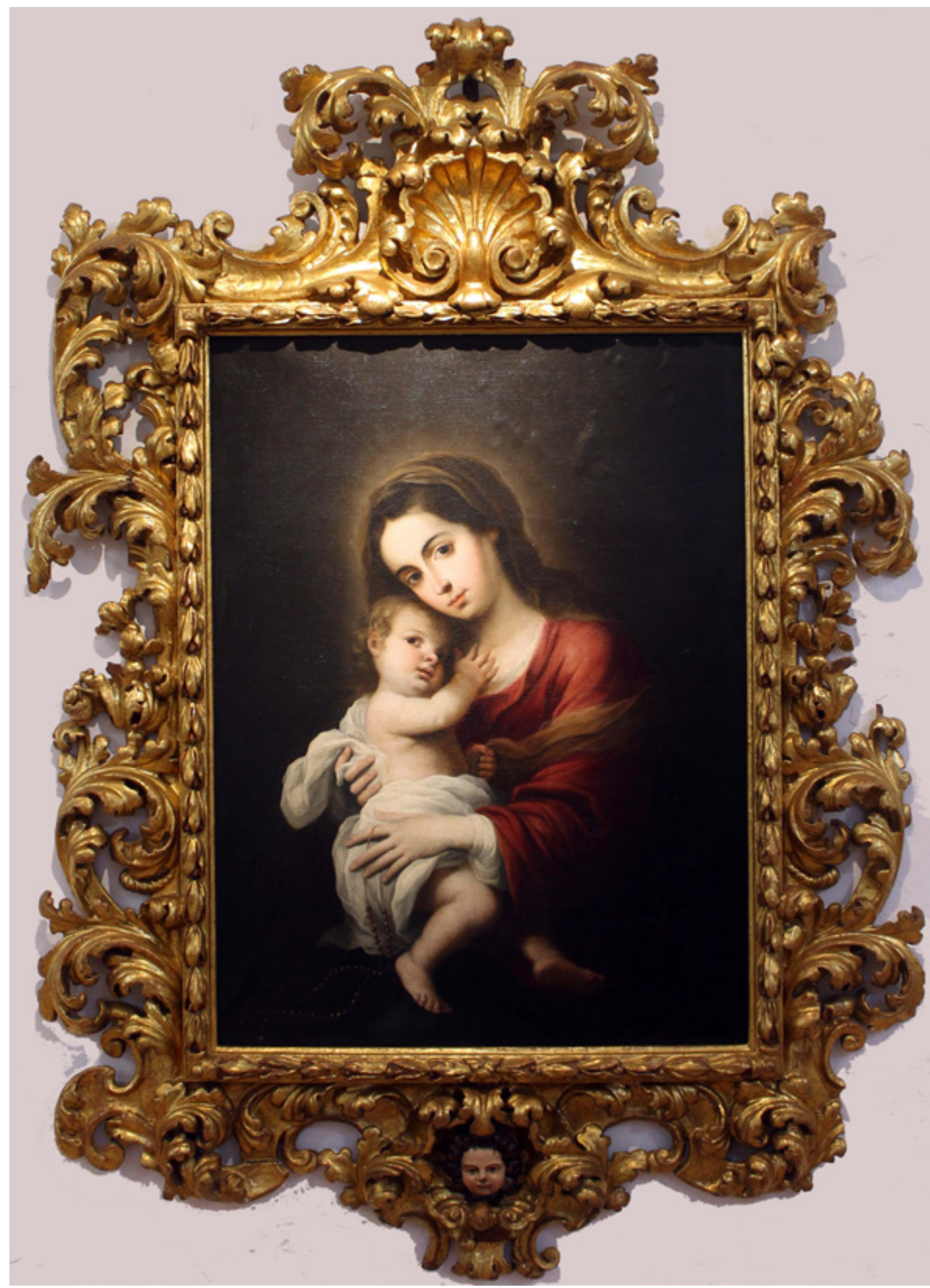

Figura 6. Seguidor de Murillo, Virgen del Rosario, 1651-1700. Foto: Carlos Fernández. 


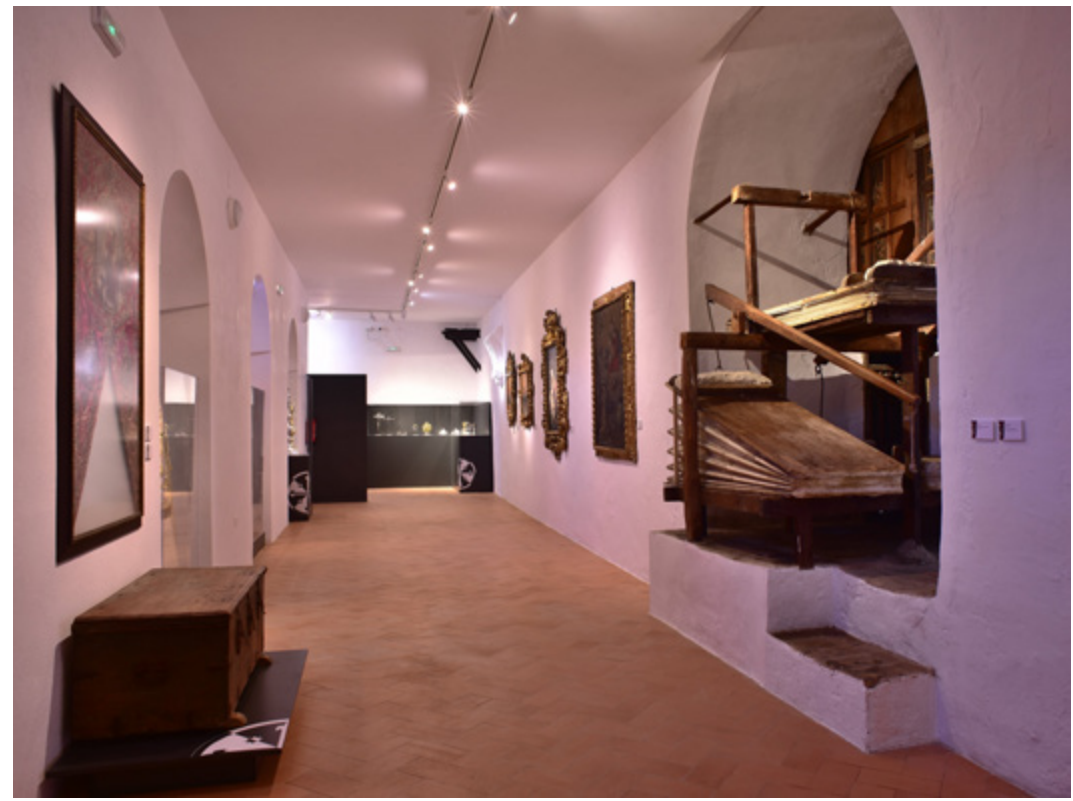

Figura 7. Perspectiva de la colección museográfica Ordo Praedicatorum con la trasera del órgano de hacia 1760. Foto: Oscar González.

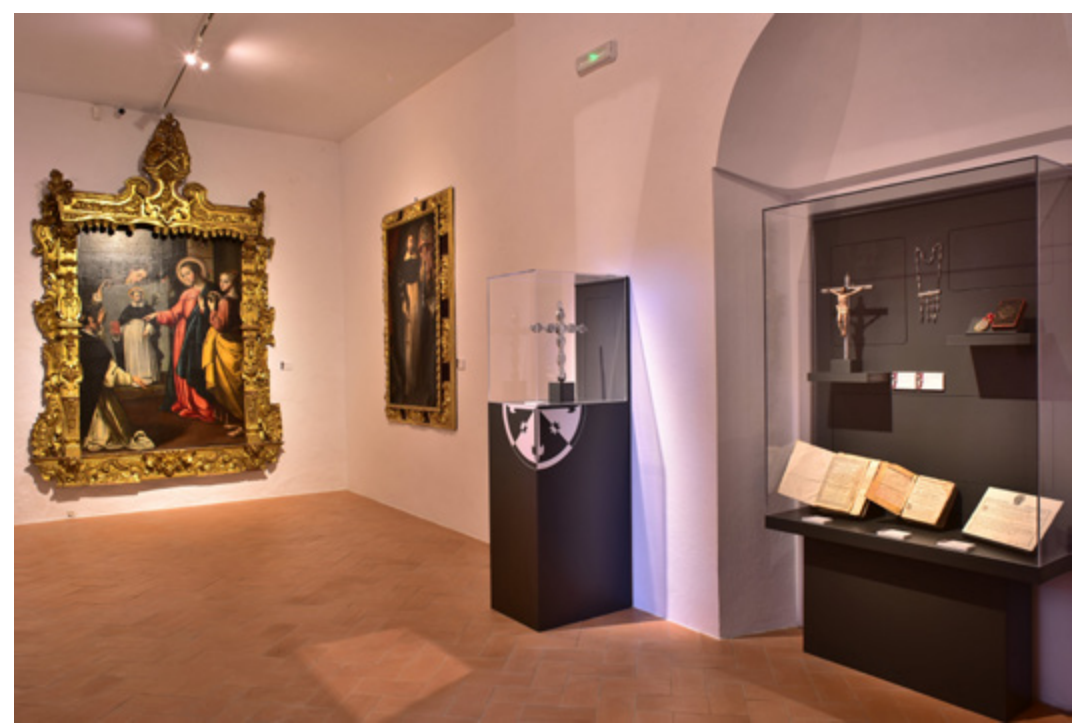

Figura 8. Vista de la sección Veritas, presidida por el Santo Domingo en Soriano de Juan del Castillo. Foto: Oscar González. 